\title{
Preliminary Evaluation of the Earthquake Hazard for Underground Electric Facility Lines in Pohang City based on ArcGIS
}

\author{
Young S. Kim ${ }^{1}$, Thien Q.Tran ${ }^{1}$, Tan M. Do ${ }^{1}$, Inn J.Park ${ }^{2}$, Kyeong M.Hwang ${ }^{3}$ \\ ${ }^{1}$ Department of Civil and Environmental Engineering, Chonnam National University, Yeosu 550-749, South Korea \\ ${ }^{2}$ Department of Civil and Environmental Engineering, Hanseo University, Sosan, South Korea \\ ${ }^{3}$ Korea Electric Power Corporation Research Institude, Daejeon, South Korea
}

\begin{abstract}
Pohang, a big city of Gyeongbuk province, South Korea, is developing rapidly in every aspect, containing many important infrastructures such as seaports, industrial factories, commercial centers, and underground electric facility systems that play an integral part in the contribution of electricity stemming from nuclear power plants. The main purpose of this research is a preliminary assessment of the earthquake hazard for underground electric facility lines (UEFL) located beneath Pohang city by using ArcGIS program. About 1000 drilling boreholes were collected as a database. All of the data were processed by filtering with respect to the depths, then the SPT-N values of unknown points were estimated by interpolation. Four interpolation methods (e.g., Inverse Distance Weighting (IDW), Kriging, Natural Neighbor, and Spline) were evaluated to find the method which gives the best representation of the SPT-N value for unknown points. The IDW method was finally selected. Afterwards, the border surface between soft- and hard-soil layers, the ground rock zonation map, the dramatic change of soil condition, and the depth of structure were determined as important scales to evaluate primarily whether the structures might be in danger or not when an earthquake occurs. In this way, proposed method can be applied to whole South Korea with over 100,000 available borehole data.
\end{abstract}

\section{Introduction}

Historically, the Korean peninsula has been known as a relatively safe region with respect to the earthquake hazard due to the characteristics of its location. But experts are now warning that recent earthquakes in nearby Japan have destabilized fault lines in Korea. The seismicity of Korea is mainly controlled by the active area Gongju, Gwangju, and Yangsan Fault Zone. In recent years, more and more earthquake occurred in southeastern Korea where are nearby the border of three main plates including Eurasian plate, Philippine plate, and Pacific plate [1]. Particularly, in the last two years, two big earthquakes occurred in Pohang and Gyeongju (a neighboring city) due to Yangsan Fault system's activities, measured magnitudes were around 5.4 on the moment magnitude scale. These earthquakes are the country's strongest earthquake in modern history. Furthermore, in Pohang, there are some soft-soil area, it is necessary to analyze the earthquake hazard to minimize effectively its danger. In this paper, the ground rock surface was created and SPT values of unknown points were also predicted by utilizing the IDW method based on the collected field data. The purpose of this is to evaluate primarily whether the structures might be in danger or not when an earthquake comes in Pohang area.

\section{Methodology}

\subsection{Spatial prediction methods and criteria for} comparison

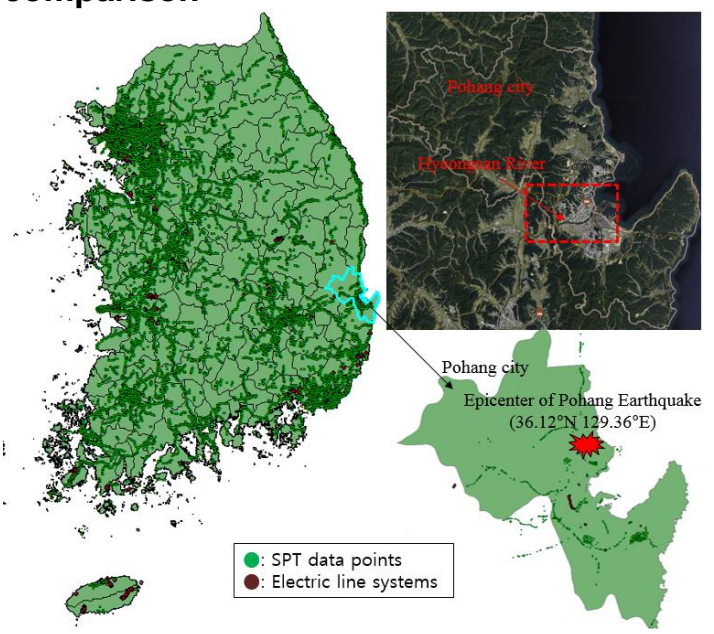

Figure 1. Data point systems, electric facilities, and map of Pohang city.

IDW estimations are based on nearby known locations. The data points (Figure 1) close to the prediction point 
have more effect on the predicted result than farther ones and vice versa. The formula of this interpolator is [2]:

$$
Z(x)=\frac{\sum_{i=1}^{n} Z\left(x_{i}\right) \cdot d_{i}{ }^{-p}}{\sum_{i=1}^{n} d_{i}{ }^{-p}}
$$

where: $\mathrm{Z}(\mathrm{x})$ is the interpolated value for the location $\mathrm{x} ; \mathrm{n}$ is the number of sample data values, $d_{i}$ is the distance from the interpolated point to the sample data point, $\mathrm{Z}\left(\mathrm{x}_{\mathrm{i}}\right)$ is the observed value at location $\mathrm{x}_{\mathrm{i}}$, and $\mathrm{p}$ denotes the weighting power.

Similar to IDW method, however, in the kriging method, the weights are based not only on the distance but also on the overall spatial arrangement of the data points. Kriging estimates the unknown values and the error prediction variance value of those points, calculated as follows [3], [4]:

$$
\begin{aligned}
& Z\left(x_{0}\right)=\sum_{i=1}^{n} \lambda_{i} Z\left(x_{i}\right) \\
& \sigma_{k}^{2}\left(x_{o}\right)=\mu+\sum_{i=1}^{n} \lambda_{i} \gamma\left(x_{o}-x_{i}\right)
\end{aligned}
$$

where: $Z\left(x_{0}\right)$ is the estimated value, $\lambda_{i}$ are the weights, $\mathrm{n}$ is the number of measured values, $\mu$ is the Lagrange constant, $Y\left(x_{0}-x_{i}\right)$ is the value corresponding to the distance between $x_{0}$ and $x_{i}$.

Spline method is similar to IDW, the Spline interpolation method fits a flexible surface as if it were stretching a rubber sheet across all the known point values. The algorithm used for the Spline tool uses the following formula for the surface interpolation:

$$
S(x, y)=T(x, y)+\sum_{i=1}^{n} \lambda_{i} R\left(r_{i}\right)
$$

where: $\mathrm{n}$ is the number of data points, $\lambda_{\mathrm{i}}$ are coefficients found by the solution of a system of linear equations, $\left(r_{i}\right)$ is the distance from the interpolated point to the sample data point, $\mathrm{T}(\mathrm{x}, \mathrm{y})$ and $\mathrm{R}\left(\mathrm{r}_{\mathrm{i}}\right)$ are defined differently, depending on the selected option (http://pro.arcgis.com).

Natural Neighbor interpolation finds the closest subset of data points to an unrecorded point and applies weights to them based on proportionate areas.

$$
\mathrm{S}(\mathrm{x}, \mathrm{y})=\sum_{\mathrm{i}=1}^{\mathrm{n}} \mathrm{w}_{\mathrm{i}} \mathrm{f}\left(\mathrm{x}_{\mathrm{i}}, \mathrm{y}_{\mathrm{i}}\right)
$$

where $S(x, y)$ the estimated value, $w_{i}$ are the weights, and $\mathrm{f}\left(\mathrm{x}_{\mathrm{i}}, \mathrm{y}_{\mathrm{i}}\right)$ is the data point at $\left(\mathrm{x}_{\mathrm{i}}, \mathrm{y}_{\mathrm{i}}\right)$

(http://pro.arcgis.com).

In this present study, in order to determine the best predictive method for the interpolation in Pohang area, a simple criterion was built. Particularly, twenty predicted points in the area were randomly selected and compared with the real SPT-N values at the corresponding depth. In this method, the most accurate method was designated 4 plus points, the second, third, and least accurate ones were 3, 2, and 1 plus points, respectively. The best method is a method getting the highest score among 4 methods and it gives predicted results closest to the real values.

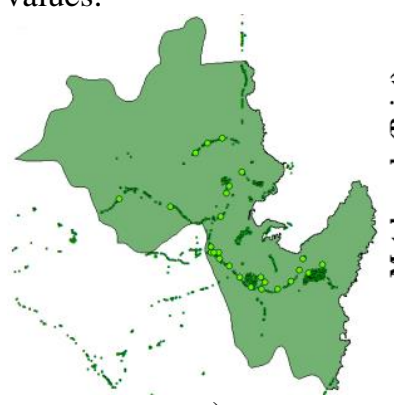

a)

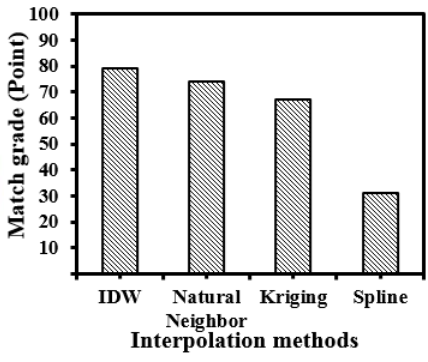

b)
Figure 2. (a) The map of training data points, (b) Match grade of 4 interpolation methods.

Figure $2 b$ shows that IDW is more accurate than the others three methods with 79 plus points, followed by Natural Neighbor, Kriging, and Spline methods with 74, 67 , and 31 points, respectively. With the distribution condition of the input data points in Pohang city as shown in Figure 2a, the result clearly shows that IDW is the best method for predicting the unknown SPT-N values in this study. This finding is a good agreement with previous studies [2], [5].

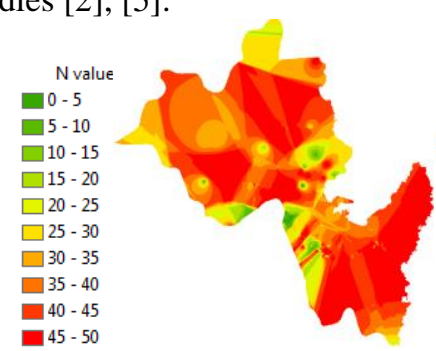

a)

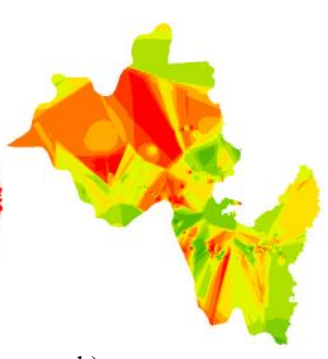

b)
Figure 3. Predicted result map at the depth of $1.5 \mathrm{~m}$ (a) and 7.5 m (b) of SPT-N value.

Figure 3 shows predicted result maps of SPT-N value at the depth of $1.5 \mathrm{~m}$ and $7.5 \mathrm{~m}$, with the dense system of the input data point that is a good condition for IDW method to optimize its advantages, the SPT-N values at unrecorded locations were effectively estimated at every depth corresponding to the nearby input data points.

\subsection{Dangerous level criteria}

\subsubsection{Criteria 1}

In this study, based on the relationship between stress ratios required to cause liquefaction and SPT- $\mathrm{N}$ values and relative density of soils with SPT-N value, SPT Nvalue of 20 is considered as a critical value for the soil to resist the earthquake hazard [6], [7]. Based on the estimated SPT $\mathrm{N}$ values using IDW around the electric facility lines, vulnerability about earthquake hazard was preliminarily evaluated. The depth of UEFL is thoroughly compared with the depth where is the border between the soft soil and hard soil layer ("N20 surface") at that 
location, and structure is considered as dangerous when its depth is shallower than "N20 surface" and vice versa. As shown below, Figure 4 presents the idea used for determining the dangerous and safe electric facility line cases.

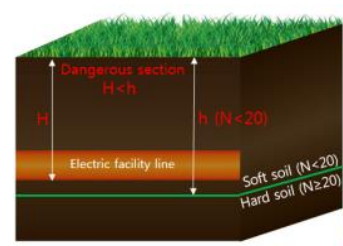

a)

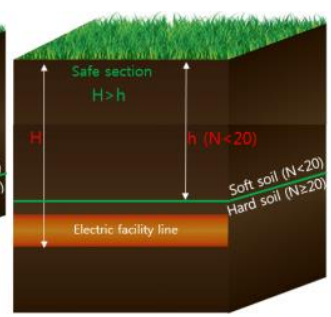

b)
Figure 4. (a) Simulation of the dangerous section and (b) the safe section.

For this work, the very first step is determining the border surface between soft- and hard-soil layers by filtering the SPT-N values that are smaller than 20 at the maximum depths. Afterwards, the IDW interpolation method was used to connect those values and predict the unknown values to create the complete border "N20 surface". Similar to the method determining "N20 surface", however, the "bedrock surface" was obtained by filtering the SPT-N values that are around 50 at the minimum depths. The fundamental methods defining the "N20 surface" and "bedrock surface" are illustrated in Figure $5 \& 6$

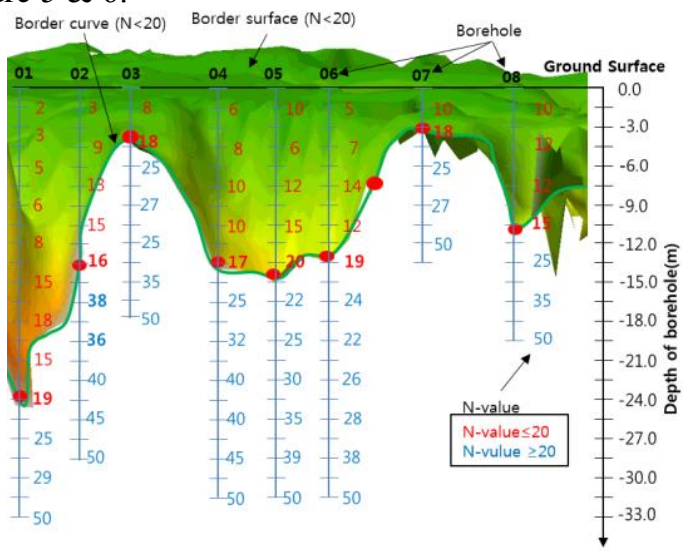

Figure 5. "N20 surface" determination method.

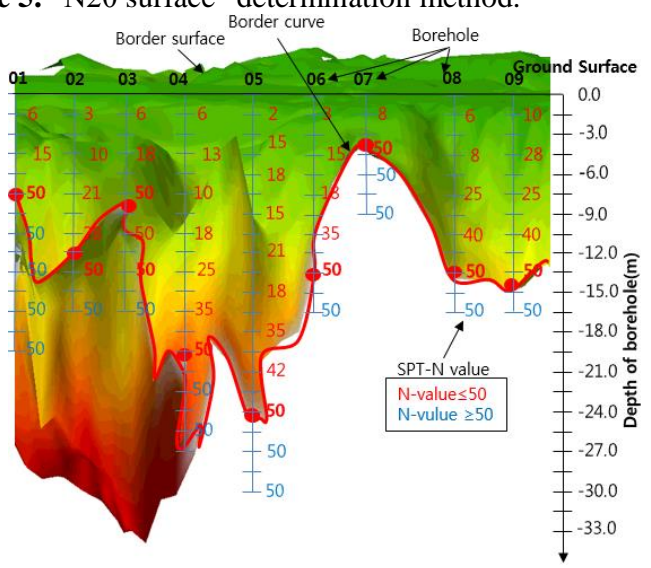

Figure 6. "Bedrock surface" determination method.

\subsubsection{Criteria 2}

Figure 7 shows that criteria 2 might be one of these two conditions that cause the skew deformation of UEFL when the earthquake occurs.

The first is when the electric facility line's longitudinal depth changes dramatically from the soft soil layer to the hard and vice versa. The second case is sudden changes of the soil condition surrounding the electric facility lines, particularly, the "N20 surface" changes dramatically and cut through facilities. Thus, criteria 2 is useful for evaluate danger level in 2 different cases.

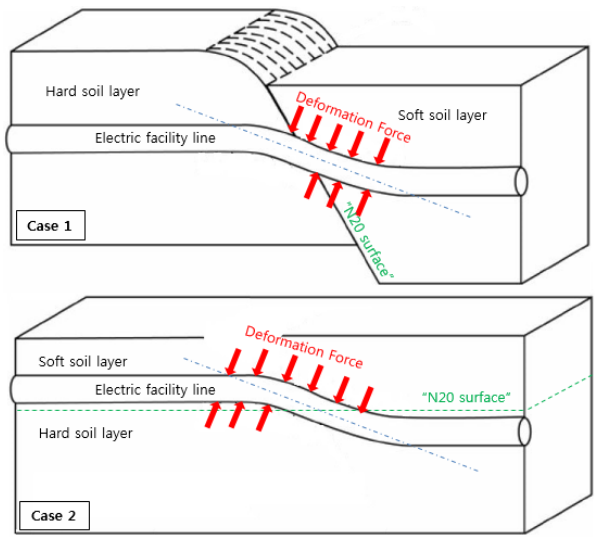

Figure 7. Explanation of two different dangerous cases.

\subsubsection{Relatively horizontal deformation (RHD)}

At case 2 shown in Figure 7, it is necessary to estimate the relatively horizontal deformation of UEFL when it fluctuates dramatically in soft soil areas or from the soft soil layers to the hard soil layers and conversely with. The magnitude of relatively horizontal deformation of soil at the structural depth is estimated by using the following formulas [8]:

$$
\Delta_{\text {free-field }}=h \cdot \gamma_{\max }, \quad \gamma_{\max }=\frac{\mathrm{Vp}}{\mathrm{Cs}}
$$

where: $\mathrm{h}$ is height of the structure, $\Delta$ free-field is free-field shear strain at the depth of the electric facility line, $\mathrm{Vp}$ is peak particle velocity at the electric facility line depth, Cs is effective shear wave velocity of ground surrounding the electric facility line that is determined based on an empirical correlation between shear wave velocity and SPT-N value for Korean soil deposits [9]. The model of the effect of RHD to the underground structure is presented in Figure 8.

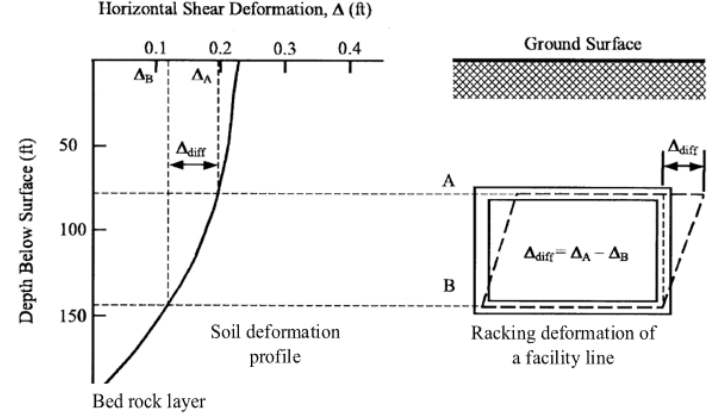


Figure 8. Typical free-field deformation affecting structures [8], [10].

The ratio of peak ground velocity $(\mathrm{cm} / \mathrm{s})$ to peak ground acceleration ( $\mathrm{g}$ ) was employed to derive the particle velocity $\mathrm{Vp}$ at the corresponding depths.

Table 1. Ratios of Peak ground velocity to peak ground acceleration at the surface in rock and soil [8], [10].

\begin{tabular}{|c|c|c|c|}
\hline \multirow{3}{*}{$\begin{array}{l}\text { Moment } \\
\text { magnitude } \\
\text { (M) }\end{array}$} & \multicolumn{3}{|c|}{$\begin{array}{l}\text { Ratio of peak ground velocity }(\mathrm{cm} / \mathrm{s}) \text { to peak ground } \\
\text { acceleration }(\mathrm{g})\end{array}$} \\
\hline & \multicolumn{3}{|c|}{ Source-to-size distance $(\mathrm{km})$} \\
\hline & $0-20$ & $20-50$ & $50-100$ \\
\hline \multicolumn{4}{|l|}{ Rock $^{a}$} \\
\hline 6.5 & 66 & 76 & 86 \\
\hline 7.5 & 97 & 109 & 97 \\
\hline 8.5 & 127 & 140 & 152 \\
\hline \multicolumn{4}{|l|}{ Stiff soil ${ }^{\mathrm{a}}$} \\
\hline 6.5 & 94 & 102 & 109 \\
\hline 7.5 & 140 & 127 & 155 \\
\hline 8.5 & 180 & 188 & 193 \\
\hline \multicolumn{4}{|l|}{ Soft soil ${ }^{\mathrm{a}}$} \\
\hline 6.5 & 140 & 132 & 142 \\
\hline 7.5 & 208 & 165 & 201 \\
\hline 8.5 & 269 & 244 & 251 \\
\hline
\end{tabular}

In order to clarify the parameters in Table 1 , the design magnitude for the earthquake in Korea is 6.5 and distance from Pohang area to the Yangsan fault zone system is within $20 \mathrm{~km}$. With the geographical location belongs to zone 2 (seismic zone) in Korea, the seismic numerical coefficient was designated $\mathrm{a}_{\mathrm{gR}}=0.11 \mathrm{~g}_{[11]}$

The site-specific Peak Ground Acceleration amax,s was given by the following equation [12]:

$$
\mathrm{a}_{\max , \mathrm{s}}=\mathrm{S} \cdot \mathrm{a}_{\mathrm{gR}}
$$

where: $\mathrm{S}$ is ground type factor [11]

As shown in Table 2, according to the ratio of ground motion at tunnel depth to motion at ground surface, the Peak Ground Acceleration at each different depth was determined from the site-specific Peak Ground Acceleration with the following relationship:

$$
\mathrm{a}_{\mathrm{z}, \max }=\mathrm{C} . \mathrm{a}_{\text {max, } \mathrm{s}}
$$

where: $\mathrm{C}$ is ratio of ground motion at tunnel depth to motion at ground surface that is derived from Table 2

Table 2. Ratios of ground motion at depth to motion at the ground surface [8], [10].

\begin{tabular}{lc}
\hline $\begin{array}{c}\text { Tunnel } \\
\text { depth }(\mathrm{m})\end{array}$ & $\begin{array}{c}\text { Ratio }(\mathrm{C}) \text { of ground motion at tunnel depth to } \\
\text { motion at ground surface }\end{array}$ \\
\hline$\leq 6$ & 1.0 \\
$6-15$ & 0.9
\end{tabular}

$15-30$

0.8

$>30$

Finally, the RHD values at corresponding depths were calculated with sufficient input parameter such as SPT-N values, shear wave velocities, the magnitude of 6.5 , peak ground acceleration, the distance between sources to study locations and height of UEFL.

\section{Results and discussion}

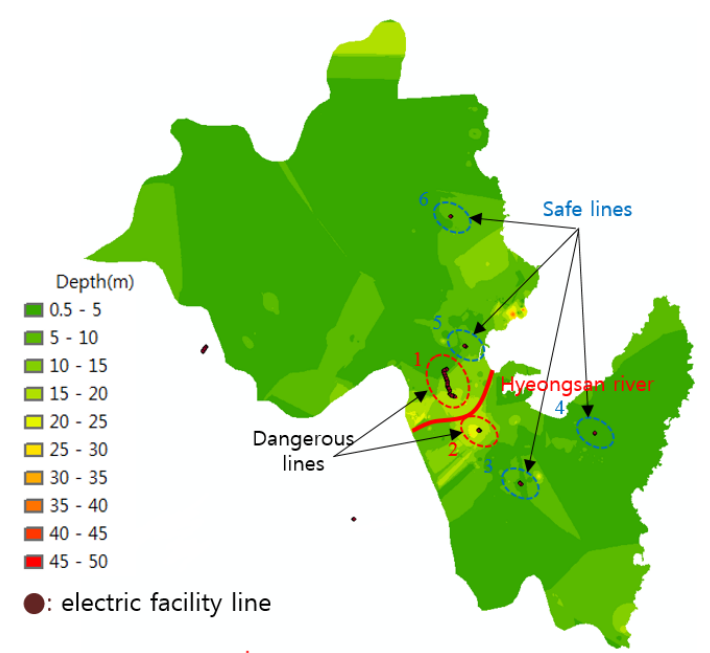

Figure 9. Zonation map of "N20 surface".

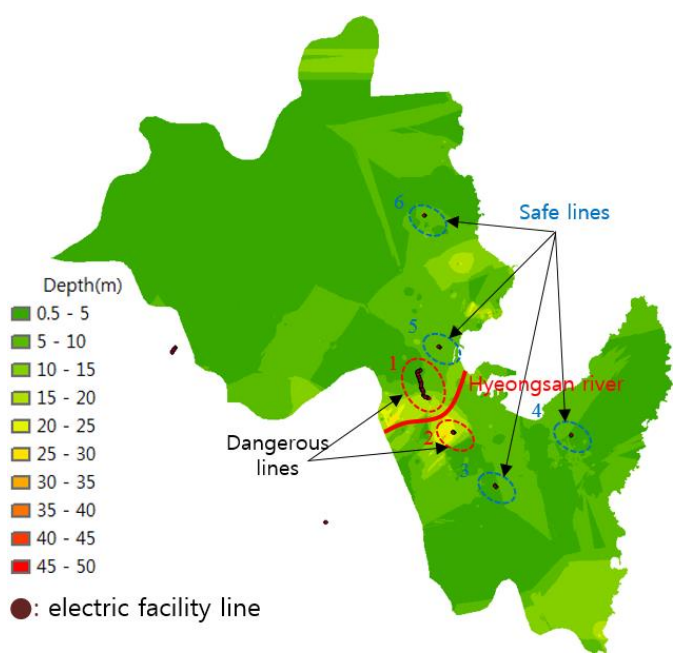

Figure 10. Zonation map of "bedrock surface".

Figure 9 shows the zonation map of "N20 surface", according to the distribution of the color spectrum results. It indicates that the "N20 surface" depth ranges from around $0.5 \mathrm{~m}$ to $35 \mathrm{~m}$ and soft soil layers are mainly located around Hyeongsan river where Line 1 and Line 2 are nearby.

Similarly, the color spectrum in Figure 10 shows the zonation map of the "bedrock surface" depth that varies in a range of $0.5-40 \mathrm{~m}$. It also indicates that the deepbedrock surface is primarily concentrated around the river, one of the agents of this distribution may be the river's alluvial activities. 
According to the distribution characteristic of the Pohang's UEFL system, it is divided into 6 main lines consist of UEFL1, 2, 3, 4, 5 and 6. The location of lines is shown in Figure $9 \& 10$.

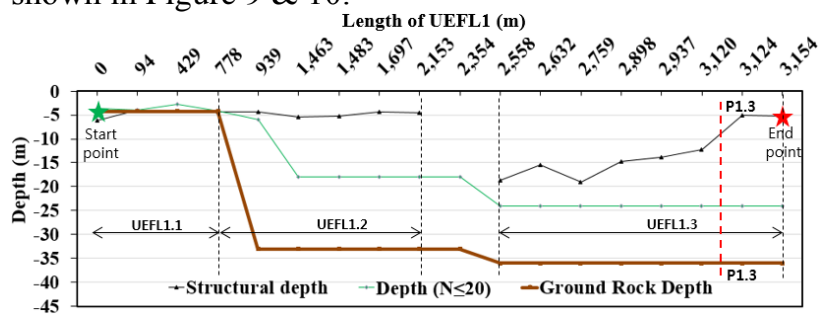

Figure 11. Longitudinal section of UEFL1 - Pohang city.

UEFL1 consists of three different types of the dangerous levels (UEFL1.1, 1.2, \& 1.3). As shown in Figure 11, UEFL1.1 is located deeper than the "N20 surface" depth and the "bedrock surface" depth. It indicates that the UEFL1.1 is buried in a good soil condition, therefore this line is considered as a safe line for both criteria 1 and criteria 2. Similarly, UEFL3, 4, 5, and 6 are also considered as safe ones based on criteria 1 and 2 .

Besides, Figure 11 also shows that UEFL1.2 is located at shallow depths that are much shallower than the "N20 surface" depths and "bedrock surface" depth. Consequently, it might be in danger based on criteria 1 .

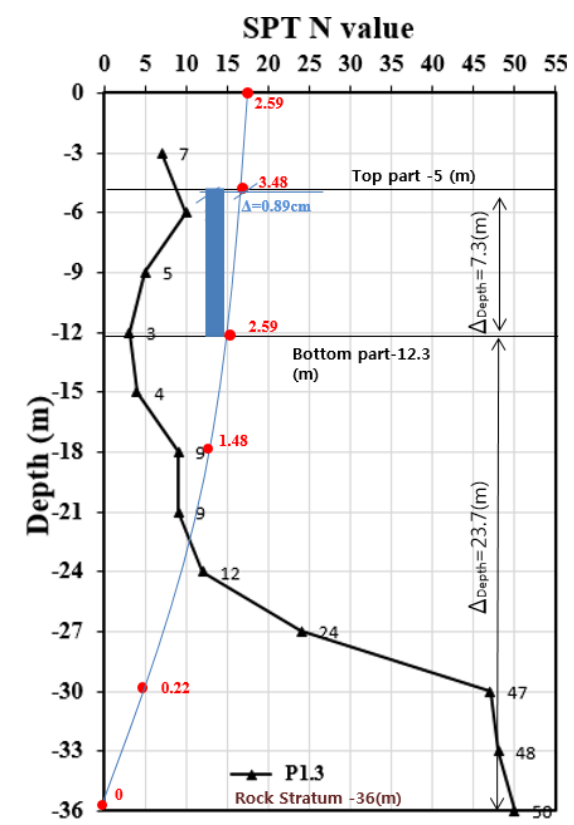

Figure 12. Vertical section P1.3 of UEFL1.3 - UEFL 1 Pohang city.

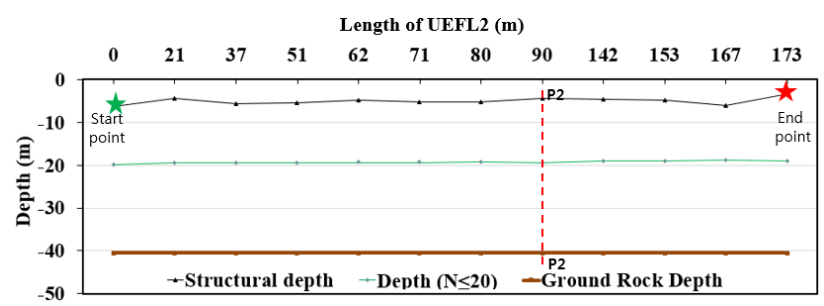

Figure 13. Longitudinal section of UEFL2- Pohang city.
In the last part of UEFL1, UEFL1.3 is placed above the "N20 surface" and "bedrock surface" at fluctuant depths. UEFL1.3 is, therefore, considered as a dangerous line for criteria 1 . Furthermore, Figure $11 \& 12$ show that there is a dramatic change of the structure depth with a different depth between the top and bottom structure's part of $7.3 \mathrm{~m}$ within the horizontal distance of $4.0 \mathrm{~m}$. Hence, the segment of UEFL1.3 including section P1.3 should be noted to be a dangerous part for both criteria 1 $\& 2$, the RHD value should be estimated for checking the flexibility of this underground electric facility segment at this location.

In case of UEFL2, Figure $13 \& 14$ indicate that there are soft-soil layers surrounding UEFL2 which is stably located shallower than "N20 surface" and "bedrock surface". Furthermore, the maximum of soft-soil depth and the minimum of bedrock depth are much deeper than UEFL2's average depth. Thus, this line might be dangerous when an earthquake comes for criteria 1.

\section{SPT N value} $\begin{array}{llllllllllll}0 & 5 & 10 & 15 & 20 & 25 & 30 & 35 & 40 & 45 & 50 & 55\end{array}$

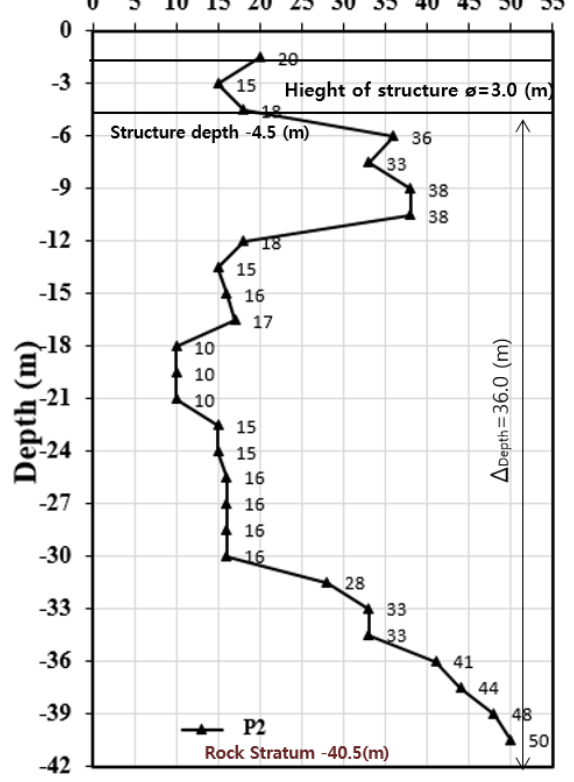

Figure 14. Vertical section P2 of UEFL2- Pohang city.

Overall, the zonation map shows that the depth of ground rock in Pohang area is generally shallow, except for UEFL1 and UEFL2 in Hyeongsan river's delta Pohang city. Typical dangerous sections are selected based on the vertical and longitudinal variations in SPT$\mathrm{N}$ value, relative horizontal deformation $\Delta$ around the structure. In addition, some sections in the line might be classified as dangerous based on the relatively horizontal deformation of the surrounding ground between the bottom and top of the structure. Based on the evaluated results from proposed method using ArcGIS, the in-situ investigation is on-going.

\section{Conclusion}

1. In this study, SPT $\mathrm{N}$ values around the underground electric facility lines in Pohang area are successfully estimated using the IDW method. 
2. Based on the interpolated SPT N values, structure depth, longitudinal change in ground condition, and estimated relative horizontal deformation during the earthquake, dangerous underground electric facility lines in Pohang area can be classified and specific sections are evaluated.

\section{Acknowledgment}

We would like to express our deepest gratitude to Korea Electric Power Corporation Research Institute (KEPCO) for financial support on this study.

\section{References}

1. Myung-Soon Jun and O. Kulhánek, "Source parameters of earthquakes in and around the Korean Peninsula deduced from spectral analysis," Phys. Earth Planet. Inter., vol. 65, no. 3-5, pp. 255-266, (1991)

2. T. P. Robinson and G. Metternicht, "Testing the performance of spatial interpolation techniques for mapping soil properties," Comput. Electron. Agric., vol. 50, no. 2, pp. 97-108, (2006).

3. S. Science and S. Of, "Soil science society of america," vol. 22, no. 3, pp. 189-192, (1958).

4. G. S. Bhunia, P. K. Shit, and R. Maiti, "Comparison of GIS-based interpolation methods for spatial distribution of soil organic carbon (SOC)," J. Saudi Soc. Agric. Sci., (2016).

5. S. Naoum and I. K. Tsanis, "Ranking spatial interpolation techniques using a GIS-based DSS," Glob. Nest J., vol. 6, no. 1, pp. 1-20, (2004).

6. H. Bolton Seed, K. Tokimatsu, L. F. Harder, and R. M. Chung, "Influence of SPT Procedures in Soil Liquefaction Resistance Evaluations," J. Geotech. Eng., vol. 111, no. 12, pp. 1425-1445, (1985).

7. K. Terzaghi, R. B. Peck, and G. Mesri, "Soil Mechanics in Engineering Practice." pp. 1-529, (1996).

8. F. T. Manual and R. Tunnels, "FHWA-NHI-10-034 Errata Sheet Foreword," English, (2008).

9. C. G. Sun, C. S. Cho, M. Son, and J. S. Shin, "Correlations Between Shear Wave Velocity and InSitu Penetration Test Results for Korean Soil Deposits," Pure Appl. Geophys., vol. 170, no. 3, pp. 271-281, (2013).

10. Y. M. A. Hashash, J. J. Hook, B. Schmidt, and J. IChiang Yao, "Seismic design and analysis of underground structures," Tunn. Undergr. Sp. Technol., vol. 16, no. 4, pp. 247-293, (2001).

11. K. D. Standard, "Architectural Institute of Korea. Korean Building Code; Architectural Institute of Korea," (2016).

12. JRC European Commission, C. Eurocode, and International Code Council, Eurocode 8: Seismic Design of Buildings Worked examples, vol. 1, (2004). 